\title{
Promotion of Exhibition Industry to Tourism Consumption under the Background of Digital Economy
}

\author{
Hongxia $\mathrm{Wu}^{1}$ \\ ${ }^{I}$ School of tourism and art, Beijing Vocational College of Finance and Commerce \\ wuhx@bjczy.edu.cn
}

\begin{abstract}
Since the outbreak of COVID-19, tourism and exhibition industry have been hit hard, and stimulating tourism consumption will face many difficulties. In the context of digital economy, by holding small-scale and short-distance community-based exhibitions or festival activities, promoting night economic development such as tourism performance activities, concerts, and holding exhibition activities such as sports events related to healthy life, It can not only promote the recovery and development of exhibition industry and tourism industry, but also promote the consumption of tourism services. With the rapid development of digital economy, these ideas have the advantages of policy, residents' Internet penetration and information technology, so it is worth trying in the exhibition industry in the downturn. In the development of exhibition products, we should pay attention to the enhancement of consumer experience as a service product. In the context of digital economy, we should use Big Data to improve the operation and management level, realize the precise marketing of exhibition activities by using mobile Internet technology, improve efficiency and customer conversion rate, develop and run exhibition activities, and promote the growth of tourism and related service consumption.
\end{abstract}

Keywords: Digital economy, Exhibition industry, Service consumption, Precision marketing.

\section{INTRODUCTION}

In recent years, with the development of Internet+ and digital technology, the new mode of consumption characterized by online shopping, mobile payment and online-offline integration has developed rapidly. Under the background of the increasingly mature digital technology and the backdrop of COVID-19's situation, promoting domestic consumption has also become a new guide to national policies. In September, 2020, the general office of the State Council of China issued we should try every means to promote the system and mechanism of new consumption development before 2023 to 2025, improve and build the corresponding policy system, and further optimize the new business form and new mode, so as to lead the creation of new consumption development environment on Leading the Development of New Consumption with New Business Forms and New Models[1]. In this situation, service consumption under the background of digital economy is a new topic. As of January 11, 2021, through the search on CNKI with the theme of "digital economy + service consumption", the results show that there are only more than 10 literatures, including 4 Chinese literatures, such as Chen Jie (2019)[2] and Pei Changhong (2019)[3]; 5 foreign literatures, such as Udo milkau (2018) [4] think "data is new oil", Pierre Dal Zotto and others (2018) [5] think that the rapid development of information and communication technology promotes consumers' participation in the process of enterprise value creation through information exchange, which is close to real-time; Lai Yang (2015)[6] and Wang Chengrong (2020)[7] have also done relevant research. It can be seen that there are few research results on service consumption in the digital economy, and less research on exhibition industry and tourism service consumption in the digital economy. Li Junyan et al. (2020)[8] proposed the transformation and upgrading strategy of establishing digital information platform through exhibition industry in the context of digital economy to help the transformation and upgrading of exhibition industry. Therefore, under the background of COVID-19, we can take advantage of the emerging digital economy and technology to optimize 
and upgrade the exhibition industry to promote the growth of tourism consumption. For example, by developing new community fairs, community events, performances and other forms of night economy and sports events, we can upgrade and optimize some mice that are feasible under the background of the epidemic. Activities can not only develop the exhibition industry, but also promote the orderly growth of tourism service consumption.

\section{THE PROMOTION OF EXHIBITION ACTIVITIES ON ECONOMY AND THE PULLING EFFECT OF CONSUMPTION}

As for the connotation of exhibition industry, MICE is widely used in China, that is to say, exhibition industry includes exhibition, conference, incentive tourism and festival activities. Western scholars often adopt the concept of grand exhibition[9], for example, Getz (1997) [10]divides activities into cultural celebrations, arts and entertainment, commercial trade, sports, education, science, politics and various private activities. It can be seen that the understanding of the connotation of exhibition activities is very broad. In addition to the exhibitions and conferences and activities with commercial trade, educational science and political functions, they also include other festivals, celebrations, concerts, performances, trade fairs, gatherings, sports events and other private activities, among which there are many factors related to service consumption.

As for the pulling effect of exhibition activities on the economy, it can be summarized by the statement of "airplanes scatter money over the city" put forward by Mr. Mentut, the president of Munich exhibition company, Germany.[11] This statement is famous all over the world, which shows its strong economic driving role. In addition to the direct or indirect driving effect on urban economy, the effect of exhibition activities on tourism consumption can not be underestimated. As early as the 1980s, it was proposed that China should develop tourism and drive tourism consumption through exhibition activities[12], Since the outbreak of COVID-19, the world tourism and exhibition industry have been hit hard. In November 2020, ten ministries and commissions such as the Ministry of culture and tourism issued the opinions on deepening the "Internet + tourism" and promoting the high quality development of tourism. It is believed that the domestic tourism market is expected to return to the state before the outbreak as early as 2022.[13] It can be seen that the time required for the comprehensive recovery of tourism is long. In such a severe situation, tourism is in urgent need of rescue, but the impact is not only tourism, all walks of life are seriously damaged. Due to the restrictions of the epidemic on the flow of personnel, the exhibition industry based on the flow and concentration of personnel is also facing a huge dilemma. It is urgent to change and optimize the industrial model and seek the development way.

\section{SEVERAL MEASURES}

\subsection{Development of community festival activities based on smart community}

The economic driving effect of festival activities is obvious. During the festival, the number of people in the destination increased, the hotel price increased and the tourism income increased, which significantly promoted the local economic development and formed the "rising tide effect"[14]. Regionality is an obvious feature of festival activities. Based on the rapid development of smart community in recent years, the development of community festival activities based on smart community can be used as a development direction of exhibition activities. Roche (2000) divided festival activities into Mega event, special event, hallmark event and community event according to the influence of festival activities[15]. According to this classification, the first three kinds of exhibition activities have been greatly affected. According to the requirements of epidemic prevention, these festival activities have been postponed or cancelled. Although some activities in China have been carried out in an orderly manner, it will take time for full liberalization internationally. Since the outbreak of COVID-19 has made it difficult for large scale transnational, trans provincial and other major festivals, special festivals and flag festivals to be transported by large numbers of people, if the epidemic can not be ended in a short period of time, we can try to control the middle, high or low risk areas in a small controllable range according to the shortcut of the digital economy and technology. Carry out small-scale community-based interesting, cultural, shopping and other exhibitions or festival activities, so as to enrich residents' life in a limited range and drive tourism consumption.

Of course, when developing community-based festival activities, we should also consider the spatial distribution of residents' consumption during the festival, which is also a very important factor to be considered in the development of community-based festival activities. If most of the stalls are operated by foreign operators, most of the income from the festival activities will also be contributed to entities other than the local economy, [16] and the pulling effect on the local economy will also be weakened.

\subsection{Night economic development}

For the short-distance development of residents consumption, community-based fairs and communitybased festival activities can be said to expand the scope of residents' consumption from the geographical 
horizontal. There is another direction that can be developed, that is, in addition to stimulating residents' daytime consumption, we should make full use of local residents' geographical advantages that do not need long-distance mobility, develop night economy, develop tourism performing activities, and drive the upgrading of tourism consumption. This will make the market demand brought about by the night economic development more obvious.[17] This is another time dimension to stimulate consumption. In addition to enriching the residents' lives, it is another measure to improve the consumption of residents by developing the night economy through the local residents' regional advantages.

\subsection{Holding sports events}

In recent years, the national sports has become a new way of healthy life. From Wechat Friends to Marathon, the demand for national sports has also formed a huge consumer market. Especially in the context of COVID-19, sports has changed from entertainment to daily life, residents pay more and more attention to health, sports consumption enthusiasm is also unprecedented. Therefore, we can grasp the main line of sports consumption, carry out various regional or community sports events, parent-child games and smallscale exhibitions related to sports industry, so as to enhance the residents' physique and drive sports service consumption at the same time.

\section{THE ADVANTAGE OF PROMOTING CONSUMPTION BY EXHIBITION ACTIVITIES UNDER THE BACKGROUND OF DIGITAL ECONOMY}

\subsection{Policy advantages}

No matter in accelerating the development of digital economy, promoting consumption, or the transformation and upgrading of exhibition industry, all departments of China have corresponding policy support, such as the above-mentioned opinions issued by the Ministry of culture and tourism and various policy documents issued by the general office of the State Council. With regard to the development of digital economy, the state strongly advocates it. Since the "National Big Data Strategy" was first proposed in 2015, the policies to promote the development of digital economy and digital transformation have been continuously deepened and implemented. The G20 Digital Economy Development and Cooperation Initiative adopted by the G20 Hangzhou summit in 2016 has made a clear definition of digital economy. Digital economy refers to a series of economic activities that use digital knowledge and information as key production factors, modern information network as an important carrier, and the effective use of information and communication technology as an important driving force for efficiency improvement and economic structure optimization. There are several different views on the characteristics of digital economy, but generally speaking, digital economy has the characteristics of virtuality, high additionality, high permeability, value-added, diminishing marginal cost, external economy and so on. In November 2019, the National Digital economy Innovation and Development pilot zone will be launched in Hebei Province (Xiong'an New Area). In April 2020, the data will be written into the policy document as a new production factor. In July 2020, the National Development and Reform Commission and other 13 departments jointly issued the opinions on supporting the healthy development of new formats and new models, activating the consumer market and promoting the expansion of employment. The purpose is to develop the new formats and new models in a healthy way, so as to activate the consumer market, further promote and expand employment in an all-round way, and form a virtuous circle with creating new advantages of digital economy.

In August 2020, the development report of China's digital economy 2020 issued by foresight Industry Research Institute pointed out that digital economy has become a new driving force for the high-quality development of China's national economy, and the added value of digital economy has increased from 2.6 trillion Yuan in 2005 to 35.8 trillion Yuan in 2019. At the same time, the proportion of digital economy in GDP has increased year by year, from $14.2 \%$ in 2005 to $36.2 \%$ in 2019 . According to the latest report on China's digital road, it is estimated that the average annual growth rate of China's digital economy will remain at about $15 \%$ from 2020 to 2025. By 2025, the scale of digital economy is expected to exceed 80 trillion Yuan; by 2030 , the volume of China's digital economy is expected to exceed one million billion Yuan. It is estimated that by 2025 , the digital economy will drive the number of employment in China to reach 379 million.

In this context, using digital economy to develop exhibition industry and promote consumption has great policy advantages.

\subsection{Internet penetration is high, and consumers' digital literacy is high}

Under the background of digital economy, exhibition activities to promote consumption also have advantages in Internet penetration and digital literacy. At first, the rapid increase in the number of resident Internet users. According to the 46th statistical report on Internet development in China, "as of June 2020, the number of Internet users in China is 940 million, accounting for $18.7 \%$ of Internet users aged $40-49$, and 
the proportion of Internet users aged 50 and above has increased from $16.9 \%$ in March 2020 to $22.8 \%$ "[18], It can be seen that the popularity of the Internet among middle-aged and elderly people has increased significantly. Secondly, the concept of online consumption has been deeply rooted in the hearts of the people. Not only young people, but also middle-aged and old people are very willing to buy products or services online. Third, we must pay attention to the fact that the digital literacy level of the younger generation is relatively high. With the rapid development of digital economy and the increasing independent consciousness of young people, the individual needs of consumers will be further explored through fast and convenient digital technology means, so as to make the diversified and customized consumption characteristic, arouse the attention of some specific groups, and become a consumption hot spot. Compared with the relatively cautious and conservative attitude of the post-80s generation, the post-90s, post-00s and other young consumers belonging to the digital indigenous generation are more willing to share their own data. This provides an unprecedented opportunity for enterprises to obtain consumers' consumption intention and propensity. Therefore, enterprises can make more detailed and characteristic product plans based on this, and provide more personalized and targeted products and services. According to China's Consumer Market Development Report 2020, the number of such customized orders has increased significantly.[19]

\subsection{Technological progress reduces marketing costs}

Nowadays, the consumption concept and consumption mode of the public have been inevitably impacted by the digital economy. With the progress of technology and the high penetration of the Internet, the Internet has a lot of information and interactive function. Exhibition enterprises can obtain customers' consumption intention and tendency quickly and conveniently, which reduces the cost of establishing customer database. At the same time, these can let consumers participate in the decision-making of products, not only to meet the needs of consumers, but also to design exhibition products that consumers are satisfied with. In addition, the development of information technology breaks the space limitation of traditional marketing, shortens the publicity time, and reduces the intermediate links, so that consumers and exhibition product service providers can communicate directly, which improves the marketing effect and reduces the marketing cost. Network marketing is bound to become the main marketing mode of most exhibition enterprises in the future.[20] This can also attract good target customers, bring good development space for exhibition products, and form high-quality brand products, which is also the guarantee for the sustainable development of exhibition enterprises.

\section{SOME SUGGESTIONS}

Although under the background of digital economy, exhibition enterprises can not only partially solve their own difficulties by developing community festivals, sports events, developing night economy and other ways, but also revitalize the development of local tourism industry, and promote residents' service consumption, they should pay attention to the following aspects in product development concept, marketing and other aspects to develop consumer services under the background of digital economy Suggestions on business exhibition activities.

\subsection{Service consumption should focus on enhancing consumers' sense of experience}

Service consumption, especially tourism consumption, is a process in which consumers connect with the outside world through individuals, in which consumer experience is very important. The product image and brand construction of exhibition activities are inseparable from the infrastructure construction and supporting services of the destination. If we want to develop community-based trade fairs, festival activities and sports events, we must first fully understand the infrastructure environment and supporting facilities of the destination, and do full research, for example, whether the toilet, catering, accommodation, transportation and related equipment in or near the venue can meet the needs of special period, whether the quantity is enough, and whether the location is reasonable. These factors, which seem to have no direct relationship with the exhibition activities, directly determine the consumers' experience in the process of service purchase. Only the activities that make consumers feel good experience can be truly sustainable. Therefore, while improving the modern information technology of exhibition activities, the exhibition activities that belong to service consumption should still focus on enhancing consumers' experience while taking into account their own interests and social interests.

In the era of digital economy, with the continuous maturity of digital technology, the boundary between supply side and demand side is increasingly blurred. The supply side and the demand side become integrated "producers and consumers", that is, the producers participating in production activities are also consumers, and consumers gradually participate in the production on the supply side. "Integration of production and consumption" reveals the development trend of the digital economy era, and also makes the supply side look at consumers from a new height. Therefore, 
exhibition enterprises should effectively discover and analyze the behavior patterns of festival participants by using Big Data technology, help enterprises identify the changes of customers' demands for certain products or services at any time, guide enterprises to focus on customer demand, carry out personalized product design and product marketing promotion activities better, and provide more targeted after-sales services for customers Business, to attract customers of exhibition activities and promote urban consumption.

\subsection{Using Big Data to improve operation management}

Different from traditional exhibition activities, under the background of digital economy, the project approval, creativity, design, preparation, operation, publicity, marketing and project management of exhibition activities are faster and more convenient, which greatly saves time, manpower and material resources, Therefore, we must use technical means to optimize and improve the operation and management of exhibition projects. For example, online booking of tickets is used when participating in the activities, Big Data is used for security inspection, the number of people at the activity site is controlled to $75 \%$ of the normal flow of people by quick scanning of tickets or reservation code, and the feedback data of consumer experience is obtained quickly and conveniently. At the same time, information technology is used to implement collaborative management for on-site audience, exhibitors, event organizers, guests, media and suppliers, so as to improve efficiency, reduce costs, and vigorously improve the operation and management level of exhibition activities, so as to lay the foundation for building brand and long-term exhibition activities.

\subsection{Using mobile Internet technology to realize precise marketing of exhibition activities}

Since the concept of exhibition precision marketing was put forward, it has gone through three stages. The first stage is the phase of people-search-information, that is, people search for information they are interested in through search engines. The second stage is the phase of human-search-human, that is, micro blog and Wechat era to carry out accurate marketing through social media. Now, it has developed to the third stage, namely, it mainly realizes information search people through mobile APP and mobile programmed advertising in the mobile Internet era. Due to the development of mobile Internet technology, the data of the information age is dead, but he data in the information search era is alive. Customers interested in some or some kind of exhibition activities can be accurately found through mobile APP and some advertisements processed by the program. This precision marketing is undoubtedly more efficient. Therefore, in this context, the organizers of exhibition activities should make use of technical means to make every advertisement information promoted through the Internet can take the initiative to accurately find potential target customers, carry out efficient, fast and accurate marketing, and improve the customer conversion rate.

\section{CONCLUSION}

When tourism consumption and exhibition industry suffer heavy losses, stimulating consumption will face many problems. However, holding small-scale and short-distance exhibition activities can not only promote the recovery of exhibition industry, but also gradually promote tourism industry, and also promote residents' tourism service consumption, such as the development of community-based fairs or festival activities, the promotion of tourism performance activities, concerts, concerts and other night economic development, as well as the holding of healthy life related sports events, to improve the health of residents at the same time, drive the growth of sports service consumption. With the rapid development of digital economy, these ideas not only have the advantages of policy, but also have the advantages of a large increase in the proportion of Internet users. In addition, they also have the advantages of cost reduction brought by the development of information technology. Therefore, it is worth trying in the exhibition industry in the downturn. In the development of exhibition products, we should pay attention to that as a service product, we need to enhance the sense of consumer experience as the center. Under the background of digital economy, we should use Big Data to improve the level of operation and management, use mobile Internet technology to achieve precise marketing of exhibition activities, and improve the efficiency and customer conversion rate. Only by truly developing and running these exhibition activities, we can drive the consumption of tourism and tourismrelated services increased.

\section{ACKNOWLEDGMENTS}

The research was supported by General Project of Beijing Education Science in the 13th Five Year Plan 2020:The Research of Training Mechanism of International Talents for Exhibition Professionals under the Background of "One Belt, One Road" (ACDB2020181); The general research project of Beijing Vocational College of Finance and Commerce 2021: "Research on transformation, upgrading and Countermeasures of online exhibition under the background of digital economy " (BJCZY2021C11); The project of Ideological and Political teaching reform in school of Tourism and Art of Beijing Vocational College of Finance and Commerce :"Research on the ideological and political construction and practice of exhibition project planning and management 
course"(CZLYXY2021001); Key research project of Beijing Vocational College of Finance and Commerce 2020:Research on Teachers' International Literacy in new business colleges(CZYB202003).

\section{REFERENCES}

[1] Opinions of the general office of the State Council on accelerating the development of new consumption led by new formats and new models, http://www.gov.cn/zhengce/content/202009/21/content_5545394.htm?trs=1

[2] Chen Jie. 2019. Alibaba digital economy becomes the main engine of China's new consumption upgrading. Mall modernization, 8, (Aug.2019), 22-23

[3] Pei Changhong.2019. High quality development: Ten Trends of China's economy. Economic guide, 7, (Jul 2019), 45-48

[4] Laiyang, Kangjian. 2015, The idea of improving the quality of living services in the era of "cloud consumption". Business economy research, 20, (2015), 14-16

[5] Wang Chengrong, Wang Chunjuan. 2020. Thoughts on accelerating the construction of intelligent community business service system in the "post new crown era". Research on business economy, 12,(Dec 2020), 05-09

[6] Udo Milkau. The GDPR: Halfway between consumer protection and data ownership rights, Journal of Digital Banking, 2018-08-29.

[7] Pierre Dal Zotto, Sylvain Colombero;Federico Pigni;Meyer Haggège , Customers becoming creators: how firms leverage technology and consumers for new value, Journal of Business Strategy, 2018-07-16.

[8] Li Junyan, Li Xinnuo, Zhou Chengfeng, Fang Ziqiang. 2020. Research on the transformation and upgrading of exhibition industry under the background of digital economy. Commercial exhibition economy, 7, (Jul 2020) , 17-20

[9] Wang Chunlei, Chen Xiaolian. 2013. Principles, methods and cases of activity management. Beijing: Tsinghua University Press, 2013

[10] Julia Thum, Philippa Norton and Niwa white. Translated by Tao Tingfang and Liao Qian. October 2008: 12.Festival operation management. Gezhi publishing house, Shanghai People's publishing house, Shanghai, China
[11] Deng Pu'an. 2004. "Exhibition economy" spreading money over the city. Shanghai economy, 3, (Mar 2004),21-23.

[12] Liu Dake. 2006. Empirical analysis of Beijing exhibitors' tourism consumption expenditure. Journal of tourism, 3, (Mar 2006), 73-76

[13] Yan Xiangjun: in 2021, 20 things may happen to the culture and tourism industry, and a new era will come,

http://mp.weixin.qq.com/s?_biz=MzA4MDM5NT YyNA==\&mid $=2653782083 \& i d x=2 \& s n=a 1801 \mathrm{f0}$ 8f2ff6cb79ebc22a9a323eedd \&chksm $=847$ dcc 44 b3 0a4552866f38b2db33c111c21ce70b490fd9daad69 8bb5a57218ef0b4fd72f29b1\&mpshare $=1 \&$ scene $=1$ \&srcid=0102eejN42UlI6s73gmwWvO7\&sharer_sh aretime $=1609551146420 \&$ sharer_shareid $=39165 \mathrm{~b}$ 624475e7a57ae8b746926ff19d\#rd

[14] Festivals, special events, and the “rising tide" , Stephen Litvin;;Bing Pan;Wayne Smith.International Journal of Culture, Tourism and Hospitality Research, 2013-06-15

[15]Baidu,Encyclopedia,https://baike.baidu.com/item/\% Е8\%8А\%82\%Е4\%ВA\%8B\%Е6\%B4\%BB\%Е5\%8 A\%A8/4804606?fr=aladdin\#ref_[2]_3059915

[16] Patrick T. Long .The Economic Impact OfRural Festivals And Special Events: Assessing The Spatial Distribution Of Expenditures. Journal of Travel Research: 1990-04-15

[17] The market scale of cultural tourism will reach 10trillion in the next five years, and tourism performance will lead the development of the industry,https://www.163.com/dy/article/FV9VEE CQ0534H26R.html

[18] State Internet Information Office: the 46th statistical report on Internet development in China, http://www.cac.gov.cn/202009/29/c_1602939918747816.htm

[19] Report on the development of China's consumer market in 2020, the latest report of the Ministry of Commerce: new consumption leads the domestic cycle,https://www.163.com/dy/article/FTSO91S90 534H26R.html

[20] Wu Yuwei, Liu Suhui. 2020.Research on the development of exhibition economy from the perspective of Internet. Commercial exhibition economy. (Jul 2020), 5-8 